\title{
Heat transfer coefficient $\alpha$ of insulation liquid used in power transformers, based on measurements
}

\author{
Przemyslaw Goscinski ${ }^{1}$, Zbigniew Nadolny ${ }^{1, *}$ \\ ${ }^{1}$ Poznan University of Technology, The Faculty of Electrical Engineering, 3A Piotrowo Str., 60-965 Poznan, Poland
}

\begin{abstract}
Proper work of the power transformer is determined by many factors. One of them is relatively low operating temperature of the transformer. Too high temperature has many negative consequences, such as fast aging process of the insulation system. The temperature depends on the load of transmission line, losses and heat exchange in transformer. Heat exchange depends on heat transfer factor $\alpha$ of insulation liquid, which is a component of insulation system of transformer. This factor depends on many factors: the type of insulation liquid, the length of the heating element (windings), temperature, winding surface heat load, the winding position (vertical, horizontal), place on the winding (upper, middle or bottom part). The article presents the results of the measurement of heat transfer factor $\alpha$ as a function of type of insulation liquid, winding surface heat load, and place on the windings. The results will be used by designers and operators of power transformers.
\end{abstract}

\section{Introduction}

Power transformer is one of the more crucial and sensitive part of electric power system. Its proper work depends on many factors, such as relatively low temperature [1-3].

Too high temperature has many negative consequences. It means first of all very fast ageing process of insulation system [4]. In accordance with the law of Montsinger, the increase in temperature by $5^{\circ} \mathrm{C}$ causes double reduction of lifetime of insulation system (cellulose paper impregnated by mineral oil). There are many reasons of the reduction, caused by high temperature, such as the decrease of breakdown voltage, the decrease of electrical resistance, the increase of dielectric losses, the cracking the polymer chains of cellulose, and the increase of acid number of oil [5-8]. In addition, the temperature rise may also contribute to the ignition of oil [9].

The temperature of power transformer depends on many factors. These include the load of electric power system, the losses in the transformer, and the effectiveness of transformer cooling system. The load of electric power system (current) decides on the losses in the windings of transformer. Losses in the transformer occur first of all in the windings $(80 \%)$ and core $(20 \%)$. The effectiveness of the cooling system depends on many factors, such as thermal conductivity coefficient $\lambda$ of insulation paper (paper impregnated with liquid) and heat transfer coefficient $\alpha$ of insulation liquid. If the values of these coefficients are larger, the cooling system has a higher efficacy [10].
There is usually one value of coefficient $\alpha$ in literature, and catalogs of the liquid producers (for mineral oil - the more popular insulation liquid used in transformers). Meanwhile, the authors study suggests that this coefficient may be very different, because it depends on many factors, like the type of insulation liquid, the length of the heating element (the length of the windings), the position of the heating element (vertical, horizontal), the place on the element, and the heat load of the heat element surface.

\section{Motivation and range of investigations}

Measurements of heat transfer coefficient $\alpha$ of insulation liquid as a function of the type of the liquid, the place on the heat element, and the heat load of the heat element surface were a purpose of investigations.

Four types of the liquid were investigated: mineral oil, natural ester, synthetic ester and natural ester with reduced viscosity. Three places on the heat element were analyzed: upper, middle, bottom. Three values of the heat load of the heat element surface $p$ were considered: 1000,2000 , and $3000 \mathrm{~W} \cdot \mathrm{m}^{-2}$. The length of the heat element was $1600 \mathrm{~mm}$, and its position was vertical.

\section{Results of measurements}

Table 1 presents the results of measurement of heat transfer coefficient $\alpha$ of insulation liquid. The coefficient was defined on the basis of following formula:

$$
\alpha=p /\left(T_{1}-T_{2}\right)
$$


where $\alpha$ - heat transfer coefficient of insulation liquid, $\mathrm{W} \cdot \mathrm{m}^{-2} \cdot \mathrm{K}^{-1}, T_{1}$ - temperature on heat element surface, ${ }^{\circ} \mathrm{C}$, $T_{2}$ - temperature on the cooling surface, ${ }^{\circ} \mathrm{C}$.

Table 1. Heat transfer coefficient $\alpha$ as a function of type of insulation liquid, heat load on the heat element surface $p$, and place on the heat element (upper, middle, bottom part).

\begin{tabular}{|c|r|r|r|}
\hline $\begin{array}{c}\text { Heat load } \\
p\left[\mathrm{~W} \cdot \mathrm{m}^{-2}\right]\end{array}$ & \multicolumn{1}{|c|}{1000} & \multicolumn{1}{|c|}{2000} & \multicolumn{1}{|c|}{3000} \\
\hline Type of liquid & \multicolumn{3}{|c|}{ mineral oil } \\
\hline Upper & 61.48 & 74.22 & 103.95 \\
\hline Middle & 72.08 & 112.71 & 128.21 \\
\hline Bottom & 155.96 & 217.82 & $\underline{235.42}$ \\
\hline Average & $\mathbf{9 6 . 5 1}$ & $\mathbf{1 3 4 . 9 2}$ & $\mathbf{1 5 5 . 8 6}$ \\
\hline Type of liquid & \multicolumn{3}{|c|}{ natural ester } \\
\hline Upper & $\underline{52.51}$ & 69.09 & 99.36 \\
\hline Middle & 70.32 & 108.04 & 123.59 \\
\hline Bottom & 130.66 & 191.14 & 219.91 \\
\hline Average & $\mathbf{8 4 . 5 0}$ & $\mathbf{1 2 2 . 7 6}$ & $\mathbf{1 4 7 . 6 2}$ \\
\hline Type of liquid & \multicolumn{3}{|c|}{ synthetic ester } \\
\hline Upper & 54.70 & 70.92 & 89.78 \\
\hline Middle & 69.60 & 107.25 & 121.12 \\
\hline Bottom & 135.57 & 186.28 & 204.66 \\
\hline Average & $\mathbf{8 6 . 6 2}$ & $\mathbf{1 2 1 . 4 8}$ & $\mathbf{1 3 8 . 5 2}$ \\
\hline Type of liquid & natural ester with reduced viscosity \\
\hline Upper & 60.81 & 73.45 & 103.79 \\
\hline Middle & 71.13 & 110.17 & 125.25 \\
\hline Bottom & 140.24 & 194.49 & 223.92 \\
\hline Average & $\mathbf{9 0 . 7 3}$ & $\mathbf{1 2 6 . 0 4}$ & $\mathbf{1 5 0 . 9 9}$ \\
\hline
\end{tabular}

Type of insulation liquid has influence on heat transfer coefficient $\alpha$ of the liquid. Mineral oil has the biggest value of the coefficient, then natural ester with reduced viscosity, natural ester and synthetic ester. The difference between the best and the worst liquid exceeds $10 \%$, independently on heat load on the heat element surface and place on the heat element. The reason of different values of coefficient $\alpha$ is viscosity, which plays important role in heat transfer. The biggest value of heat transfer coefficient $\alpha$ of mineral oil is caused by very small viscosity of the oil (about three times), comparing to viscosity of any analysed esters.

Heat load on the heat element surface $p$ has significant influence on heat transfer coefficient $\alpha$ of insulation liquid. The increase of the heat load (from 1000 to $3000 \mathrm{~W} \cdot \mathrm{m}^{-2}$ ) causes the increase of the coefficient $\alpha$ about $60 \div 80 \%$, independently on type of the liquid and place on the heat element. The reason of increase of the coefficient $\alpha$ with the increase of the heat load is temperature. The increase of the heat load causes the increase of temperature, which reduces the viscosity and increases the specific heat of the liquid.

Place on the heat element has very significant influence on heat transfer coefficient $\alpha$ of insulation liquid. Bottom place has the biggest value of the coefficient $\alpha$ (up to three times), comparing to middle and upper place. It means that bottom place has the more effectiveness transfer of heat. Theory of heat transfer of fluid says, that heated particles of a fluid move up. It is a reason, why upper and middle place of the element has more difficult conditions to cool, comparing to bottom.

\section{Conclusions}

All analyzed factors have some influence on heat transfer coefficient $\alpha$. In case of type of insulating liquid, mineral oil has the biggest value of the coefficient $\alpha$, comparing to all analyzed esters. The increase of heat load on the heat element surface causes the increase of the coefficient $\alpha$. In case of place on the heat element, bottom place has the biggest value of the coefficient $\alpha$.

The values of the coefficient $\alpha$, presented in Table 1 , are very different. The smallest $\alpha$ is for natural ester, for heat load $1000 \mathrm{~W} \cdot \mathrm{m}^{-2}$, and for upper place on the heat element, $52.51 \mathrm{~W} \cdot \mathrm{m}^{-2} \cdot \mathrm{K}^{-1}$ (underlined in Table 1 ). The biggest is for mineral oil, for heat load $3000 \mathrm{~W} \cdot \mathrm{m}^{-2}$, and for bottom place on the heat element, $235.42 \mathrm{~W} \cdot \mathrm{m}^{-2} \cdot \mathrm{K}^{-1}$.

On the basis on formula (1), it is possible to create a formula, which describes the temperature decrease in power transformer $T_{1}-T_{2}$ :

$$
\left(T_{1}-T_{2}\right)=p / \alpha
$$

If we use extreme different values of coefficient $\alpha$ to calculate the temperature decrease, we can obtain very different results, shown in Table 2. How it can be seen, the values of temperature decrease are very different ( $44.39^{\circ} \mathrm{C}$ of difference). It means that if we ignore the influence of mentioned factors on the heat transfer coefficient $\alpha$, we can make serious mistake in calculation of temperature decrease in power transformer.

Table 2. Comparison between calculated temperature decreases using different values of heat transfer coefficient $\alpha$.

\begin{tabular}{|c|r|r|}
\hline $\begin{array}{c}\text { Heat transfer coefficient } \alpha \\
\text { of insulating liquid }\left[\mathrm{W} \cdot \mathrm{m}^{-2} \cdot \mathrm{K}^{-1}\right]\end{array}$ & 52.51 & 235.42 \\
\hline Heat load $p\left[\mathrm{~W} \cdot \mathrm{m}^{-2}\right]$ & 3000 & 3000 \\
\hline Temperature decrease $T_{1}-T_{2}\left[{ }^{\circ} \mathrm{C}\right]$ & 57.13 & 12.74 \\
\hline Difference of temperature decrease $\left[{ }^{\circ} \mathrm{C}\right]$ & \multicolumn{2}{|c|}{44.39} \\
\hline
\end{tabular}

\section{References}

1. T. Rouse, IEEE Electr. Insul. Mag. 14, 6-16 (1998)

2. R. Lopatkiewicz, Z. Nadolny, Prz. Elektrotech. 84, 50-52 (2008)

3. R. Lopatkiewicz, Z. Nadolny, P. Przybylek, Prz. Elektrotech. 86, 55-58 (2010)

4. R. Lopatkiewicz, Z. Nadolny, P. Przybylek, W. Sikorski, Prz. Elektrotech. 88, 126-129 (2012)

5. H. Ran, J. Li, J. Zhang, X. Li, J. Chen, IEEE ICHVE, 1-4 (2016)

6. M. H. Hamid, M. T. Ishak, M. F. Din, N. S. Suhaimi, N. I. Katim, IEEE PECon, 54-57 (2016).

7. M. S. Mohamad, H. Zainuddin, S. A. Ghani, I.S. Chairul, IEEE PECon, 1-4 (2017)

8. J. Xie, M. Dong, L. Wang, A. Ma, IEEE ICEMPE, 414-418 (2017)

9. G. Dombek, J. Gielniak, R. Wroblewski, IEEE ISEIM, 227-230 (2017)

10. Z. Nadolny, G. Dombek, P. Przybylek, D. Przadka, IEEE CEIDP, 538-541 (2016) 